\title{
The Influence of Refugee Students' Personal Characteristics on Study Success in Online Education
}

\author{
F. Reinhardt ${ }^{1}$ (D) $\cdot$ T. Deribo ${ }^{1} \cdot$ O. Zlatkin-Troitschanskaia ${ }^{1} \cdot$ R. Happ ${ }^{1}$ • \\ S. Nell-Müller ${ }^{1}$
}

Published online: 25 September 2020

(C) The Author(s) 2020

\begin{abstract}
There is little research on the study success factors of refugee students in higher education. One approach to meeting the growing global demands is to provide online education specifically for refugees. This study examines specific personal characteristics of refugee students and their influence on success and retention in online education. Individual factors such as intrinsic motivation and language proficiency, cognitive functioning, and sociodemographic factors such as gender and country of residence influence retention of refugee students during online studies. The results indicate that sociodemographic factors (e.g., gender), cognitive factors (e.g., English proficiency), and external factors (e.g., country of residence) have a significant influence on study retention on refugee students.
\end{abstract}

Keywords Higher education · MOOCs · Online education · Refugee education · Study success factors

\section{Introduction}

Risk factors for refugees such as an interrupted educational history, a culturally different education system, and low competence in the language of the host country are not only obstacles for a possible entry into higher education (HE) but also for a future high-quality employment and successful integration in the labor market (Campion 2018; Hirano 2014; Platzer 2018). Many studies examine the risk factors for refugee students in the HE system or qualitatively describe the outcomes of support measures for successful integration (Baker et al. 2018a; Ferede 2012; Harris et al. 2015; Hirano 2014; Platzer 2018).

Apart from factors that hinder a successful entry into university education, Wong and Schweitzer (2017) identify possible factors that influence the academic success of

F. Reinhardt

f.reinhardt@uni-mainz.de

1 Department of Business and Economics Education, Johannes Gutenberg University, Mainz, Germany 
refugees: The integrative bio-ecological model states that academic success is interactively influenced by individual factors (e.g., gender, age, English proficiency, cognitive functioning), pre-migration factors (unsatisfactory language skills and interrupted education), and post-settlement factors (e.g., social support and school connectedness). The development of the model is based less on empirical research than on theoretical considerations. The aim of the present study is therefore to empirically investigate the possible influence of the theoretically relevant factors for academic success for refugee students. In particular, the focus is on individual student characteristics.

Changes in technological requirements, global demographic trends, and political developments also affect traditional HE. These changes are reflected in new concepts such as online education in the form of free digital learning initiatives (FDLs) and Massive Open Online Courses (MOOCs). The technical development makes it possible to offer high-quality HE without a physical campus (Volery and Lord 2000). Online education is also seen as a way of integrating refugees into HE (Castaño-Muñoz et al. 2018; De Waard et al. 2014). Especially in online education, the literature refers to considerable dropout rates (Khalil and Ebner 2014; Littlejohn et al. 2016; Ye and Biswas 2014) and to different factors that can influence the success of students. These include English proficiency, digital literacy, the learning environment, and their motivation (Liyanagunawardena et al. 2013). There are few results so far on the use of the MOOCs for refugees (Castaño-Muñoz et al. 2018; Reinhardt et al. 2018; Zlatkin-Troitschanskaia et al. 2018). Nor could any study be found that presents empirical results on refugees as users of the MOOCs in the context of online education. The study presented here therefore examines whether the factors identifiable in the literature for the academic success of refugee students can also predict success in online education.

The sample comprises $N=1024$ refugee students who were surveyed when starting their online studies at Kiron Open Education (Kiron; https:/kiron.ngo/) (for more details, see "Instruments and Methods"). Kiron is a non-profit company that provides refugees with access to $\mathrm{HE}$ through online education.

In the following, the state of research on the possible success factors, which are the focus of this study, is described. Previous results show that both sociodemographic factors such as gender (Packham et al. 2004) and individual student characteristics such as student motivation (Milligan et al. 2013) can influence success in online education. So far, there are few results on the areas of language proficiency (Engle et al. 2015) or cognitive functioning (Kennedy et al. 2015). As language has a decisive influence on the success for MOOCs' users from developing countries (Liyanagunawardena et al. 2013), the presentation of the state of research focuses on these factors. This is followed by a description of the research questions and the operationalization of the research constructs. "Results" describes the results; "Discussion," "Limitations," and "Conclusion" offer a critical discussion of the findings, the limitations, and the conclusion.

\section{Literature Review}

\section{Academic Language Proficiency}

In language proficiency, academic language proficiency differs from everyday language (Haag et al. 2013). The differences can be found on semantic, lexical, and syntactical levels (Haag et al. 2015). 
Academic language poses a great challenge, especially for second language learners (SLL), not only because it is used exclusively in school and university contexts (Haag et al. 2015; Schleppegrell 2001; Townsend and Collins 2009). The acquisition of the ability to read, understand, and write complex texts from an unfamiliar field takes between 5 and 7 years (OFSTED 2001).

Low academic language proficiency can also lead to higher dropout rates of the SLLs from the educational system, which in turn can lead to a lower chance of participation in HE and lower educational attainment (Grigorenko 2015). Refugee students belong to the SLL group, although their interrupted educational background can also have a negative impact on their academic language proficiency (Figueiredo et al. 2018). In addition, they are particularly vulnerable to possible cultural differences in their previous university careers and often low language proficiency in the host country (Baker et al. 2018b). The low level of language proficiency is described as one of the greatest problems for integration and educational success for refugees (Campion 2018). It should therefore be examined to what extent language proficiency has an influence on academic performance and academic success in online education.

\section{Cognitive Functioning}

Cognitive functioning is the mental ability to perceive and process stimuli (Fisher et al. 2017). This includes functions such as reasoning, language, memory (Desideri et al. 2016), and intelligence (Clifford et al. 2016; Schwenck et al. 2015). Therefore, cognitive functioning is often measured using intelligence measurements and neuropsychological testing (Morrison et al. 2015). Some of these tests are based on picturebased material, which measures parts of fluid intelligence (Kivling-Bodén and Sundbom 2003).

Studies have shown that cognitive functioning also has effects on educational performance and higher levels of cognitive functioning are associated with higher educational attainment and higher academic performance (Fisher et al. 2017; Lleras 2008). Many studies also show that intelligence is the decisive factor influencing academic performance (Puerta Morales 2015; von Stumm et al. 2011). Higher academic performance leads to higher academic success (Guerra-Carrillo et al. 2017; Lleras 2008). In the same way, the risk of prematurely dropping out from the education system is reduced (e.g., Morrison et al. 2015).

So far, however, there is little evidence on cognitive functioning and academic performance among refugee students (Wong and Schweitzer 2017). Cognitive functions can provide important insights for the successful integration of refugees beyond formal educational qualifications (Pagel et al. 2018). However, Pagel et al. (2018) did not report any connection to academic performance. It should therefore be examined whether cognitive functioning has an influence on academic performance and thus on academic success among refugee students.

\section{Study Motivation}

Non-cognitive factors are also decisive for educational success (Fonteyne et al. 2017). These include, in particular motivation, self-esteem, and a positive self-concept (Biewen et al. 2018). Non-cognitive factors are decisive to better explain group differences in 
later educational success (Lleras 2008). Motivation in particular is often associated with higher academic performance (Ogundokun and Adeyemo 2010). Students who are more motivated also exhibit a better academic performance. This also goes hand in hand with a reciprocal effect: higher performance also led to higher motivation (Afzal et al. 2010).

According to the Self Determination Theory (SDT; Deci and Ryan 1985), a distinction can be made between intrinsic and extrinsic motivation. Intrinsic motivation means the motivation to behave out of a personal desire and interest, while extrinsic motivation describes behavior because of an expected outcome (Ryan and Deci 2000). Intrinsic motivation in an education setting is, for example, to pursue learning goals and to obtain knowledge or interest in the study subject. Extrinsic motivation, for example, is associated with the goal of a good future career or good grades. While intrinsic motivation has a positive effect on academic performance, extrinsic motivation can have the opposite effect (Pedaste et al. 2015).

While the assessment of academic achievement using cognitive measures has shown valid results with traditional students, only cognitive measures are not a reliable instrument to predict academic achievement, especially among high-risk student populations (Adebayo 2008). Studies on the influence of refugee motivation on academic performance often describe highly motivated students (Joyce et al. 2010). Both extrinsic motivational factors, such as obtaining a university degree or a good job, and intrinsic factors, such as obtaining knowledge or doing something substantial, are reported (Hirano 2014). It can therefore be assumed that the motivation of refugee students could also have a decisive influence on their academic performance and possible academic success.

\section{Sociodemographic Factors-Gender}

In addition to the described individual student characteristics, sociodemographic factors also influence academic success or academic performance (Volery and Lord 2000). For refugee populations, gender is frequently mentioned as a barrier to education (Watkins et al. 2012). The situation of female refugees is often described as extremely vulnerable. Either women are already excluded from education in their home country (Hatoss and Huijser 2010; Watkins et al. 2012), or they are excluded from education in the host country due to cultural adjustment difficulties prior to education (El-Ghali and Al-Hawamdeh 2017). The perceived inequality is reflected in public life and their housing situation (Cheung and Phillimore 2017; El Jack 2012; Knappert et al. 2018). Gender norms must be adapted to the cultural rules of their country of origin and the host country at the same time. It is highly probable that they already experienced inequality pre-migration (Datzberger and Le Mat 2018; El Jack 2012). During the migration phase and in the post-settlement phase, they are exposed to a high risk of violation of and danger to their physical wellbeing (Pittaway and Bartolomei 2001). In addition, they have fewer job perspectives, career opportunities, and higher perceived work family conflicts (Knappert et al. 2018). Furthermore, concerning access to education, women have disadvantages compared with men, which can be accompanied by a low educational level (Dryden-Peterson et al. 2017). Cheung and Phillimore (2017) showed that female refugees participated less and later in language courses, indicating a poorer English proficiency than men. Nevertheless, online education could minimize 
discrimination against female refugees and provide an opportunity for access to HE. However, participation in the MOOCs is mostly dominated by men (Kizilcec et al. 2013). Statements about the participation of refugee students in particular could not be found. It should therefore be examined whether the described inequality of women with regard to academic achievement is also reflected in this study.

\section{Study Objective}

The current state of research demonstrates that academic performance is influenced by several factors. Individual factors such as academic language proficiency, cognitive functioning, and non-cognitive factors such as motivation have a major influence on academic performance. However, non-traditional students are mostly under-represented in studies investigating the influence of these factors and are often regarded as potentially risky students (O'Shea et al. 2016).

Refugees are high-risk students and have a high risk of premature dropout (Ferede 2012; Hos 2016). Only a small proportion of regular students are refugee students. They differ from regular/traditional students in their academic achievement (Baker et al. 2018b). However, little is known about the specific factors that determine the academic success of refugees (Wong et al. 2018).

To define academic success in online studies, we follow the definition of Breslow et al. (2013). On the one hand, they define academic success in the MOOCs as an achievement of good grades and, on the other hand, as staying in the course for the entire course duration. In this paper, we will examine the academic achievement of students by examining the starting and completion rates of the MOOCs, as well as success in online education by assessing the probability of remaining in the study program. The aim of this study is to describe the influence of individual factors of refugee students on academic achievement on an online learning platform (Fig. 1). This results in the following research questions (RQ):

1 What influence do cognitive and non-cognitive factors of refugee students have on MOOCs completion rates in online study?

2 What influence do cognitive and non-cognitive factors of students have on the probability of dropout from online education?

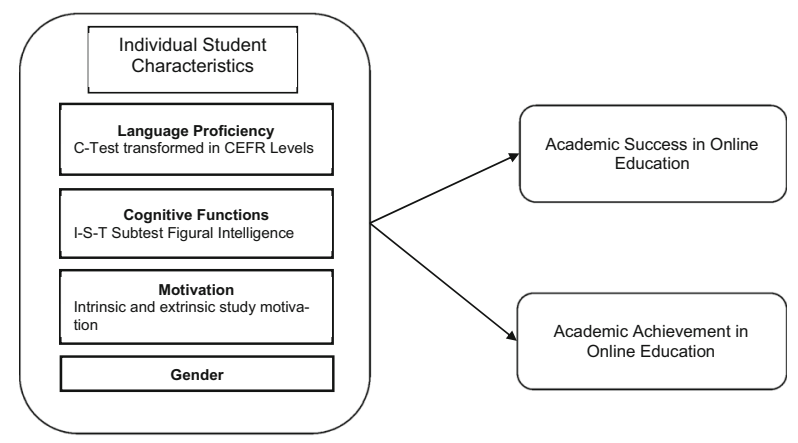

Fig. 1 Flow chart of study design 


\section{Instruments and Methods}

For RQ1, academic achievement is measured by examining the number of courses started and completed in the Business English module. This module is offered in the study track business and economics as part of the Kiron program. A total of six MOOCs are assigned to the module. The module was selected as it had already been completed at the time of this study, and the number of participants was relatively high. The participation rate in the courses was reported by the MOOC provider Coursera.

For RQ2, academic success in online studies is investigated by examining the probability of remaining in online education. For this purpose, an inactivity of 30 days on the learning platform was chosen and operationalized as a dropout criterion. We follow the approach of Halawa et al. (2014), who define this as a suitable measure to determine the dropout rate from online education.

The possible individual student characteristics in this study are English proficiency, motivation, cognitive functioning, and gender (Fig. 1). In addition, we controlled for variables that have been found to influence the educational success of refugees in online education, such as educational attainment (Greene et al. 2015) and current country of residence (Reinhardt et al. 2018).

\section{Language Proficiency}

English proficiency was measured with a $C$-test (Grotjahn 1987; Norris 2006). The $C$ test is an economically efficient instrument for assessing general language proficiency (GLP) in foreign, second, and first languages (Grotjahn 2002; Harsch and Hartig 2015) and was specially adapted for the refugees (Suter et al. 2017). The results of the $C$-test will be transferred to the Common European Framework of Reference for Languages (CEFR; Council of Europe 2001, 2018) for better comparability.

\section{Cognitive Functioning}

To measure the indicators of cognitive functioning, a non-verbal test was used to assess figural intelligence to avoid language effects. The use of matrices to measure spatial imagination is considered to be fair irrespective of culture (Rushton et al. 2007). In this study, the subtest for figural intelligence from the intelligence structure test (I-S-T 2000R; Liepmann et al. 2007) was used. Figurative intelligence is a part of fluid intelligence, which describes problem-solving abilities and logical reasoning independent of knowledge, abilities, and experience (Cattell 1987; Morrison et al. 2015). Intelligence was scaled through a 2PL-model (Birnbaum 1957). Based on the estimation model, the Expected A Posteriori (EAP; Bock and Aitkin 1981) was assessed (EAP-Rel. = .71).

\section{Study Motivation}

Study motivation was assessed using scales from the questionnaire on academic interest (FSI; Schiefele et al. 1993). In the SUCCESS project, we use the validated short scales with four items each for intrinsic and extrinsic study motivation and a four Likert scale 
as the response options (Biewen et al. 2018). Intrinsic and extrinsic motivation (IM/ EM) were scaled through a generalized partial credit model (Muraki 1992). Based on the estimation model, the EAP (Bock and Aitkin 1981) was performed (IM EAP-Rel. = .79; EM EAP-Rel. = .78).

Gender The data on the sex of the refugees interested in the study were gathered during onboarding. Gender was coded with $0=$ female and $1=$ male.

Current Country of Residence The current residence status was also collected during onboarding. The sample includes students from the host countries Germany, Jordan, Turkey, Kenya, and France.

Educational Attainment The International Standard Classification of Education (ISCED; UNESCO 2012) of the United Nations Educational, Scientific and Cultural Organization's (UNESCO) was used to assess the educational background. By using the ISCED level, international comparability is achieved. The ISCED levels are measured on a scale of $0-8$, whereby the educational levels from primary education to doctoral degree are mapped. For the analyses, the highest started educational level was used.

\section{Statistical Analyses}

For RQ1, a hierarchical regression analysis was performed to investigate the influence of the characteristics listed above on the completion probability of the MOOCs. For RQ2, the Cox regression method (Cox 1972) was performed to analyze the expected duration of time until dropout of the refugee students. Survival analyses are particularly suitable here, as the measurement of the retention rate is more meaningful than simply looking at the completion rates in the MOOCs (Greene et al. 2015).

The markers of survival rate and censoring status required for the Cox regression were operationalized as follows: The survival rate on the Kiron platform was measured as the difference in days between a student's first and last login to the Kiron platform in April $2018(M=100.18 ; S D=95.068 ; \mathrm{MIN}=0, \mathrm{MAX}=349)$. The student's censoring status $(0=$ dropout, $1=$ censored) was operationalized as 30 days since last login. If a student had not logged onto the Kiron platform for 30 days, she/he was presumed to have dropped out from the Kiron platform.

The item fit of the measured constructs was examined using mean square (MNSQ) and weighted mean square (WMNSQ) item fit statistics. Following Bond and Fox (2007), a MNSQ/WMNSQ $<0.8$ or a MNSQ/WMNSQ $>1.2$ can be considered to have a noticeable item misfit. All scales adhered to the aforementioned fit statistics $(\operatorname{Min}=.95 ; \operatorname{Max}=1.03)$.

For the use of missing values, the full information maximum likelihood (FIML) method was chosen for linear regression and the multiple imputation (MI) of missing values was chosen for Cox regression. According to Enders (2010), these represent the best methods for dealing with missing values and should make it possible to obtain non-biased parameter estimates under the missing-at-random (MAR; Rubin 1976) assumption. 


\section{Statistical Software}

For the analyses, the software R (R Core Team 2018) and Mplus (version 7.3; Muthén and Muthén 2012) were used. Within R, the packages TAM (Robitzsch et al. 2018), mice (Van Buuren and Groothuis-Oudshoorn 2010), survival (Therneau 2015), and survminer (Kassambara and Kosinski 2018) were used.

Ethical Statement Participants were informed prior to starting the assessment that their data would be used for research purposes and opted in by choosing to take the assessment or not.

Since the study describes cognitive assessment data, particular attention was paid to compliance with the AERA standards (AERA 2011) on research ethics.

\section{Participants}

The total sample consists of 1024 Kiron students (79\% male, $21 \%$ female), at an average age of 27.5 years. This sample registered on the Kiron online study platform between July and September 2017 and completed an onboarding questionnaire during enrollment. For the analyses in this study, information from the onboarding questionnaire, the English test, and the figural intelligence test were obtained, which were performed at the time of registration on the platform. The sample includes all students who come from the five largest host countries. The sample is part of the SUCCESS project, which comprises a total of 1375 students. All students who did not provide information on their educational background $(n=351)$ were excluded. Based on the descriptive characteristics (e.g., gender, age), the sample can be considered representative for refugee students enrolled in courses on the Kiron online platform (for more details, see Zlatkin-Troitschanskaia et al. 2018).

The five largest host countries are Germany with $n=360$ students, Jordan with $n=$ 251 students, Turkey with $n=184$ students, Kenya with $n=118$ students, and France with $n=91$ students. The students come from a total of 44 countries. Refugees from Syria $(n=405)$, Somalia $(n=85)$, and Afghanistan $(n=46)$ form the largest group. The students are enrolled in five study tracks: business and economics $(n=321)$, mechanical engineering $(n=79)$, social work $(n=136)$, political science $(n=103)$, and computer science $(n=385)$. Table 1 shows the distribution of the sample across the host countries and their educational degrees and language levels.

\section{Results}

\section{Descriptive Statistics}

The English level of most students is B1 with $43 \%$ in Jordan and up to $65 \%$ in Kenya (Table 1). A small proportion of refugee students have an English level of A2 or lower. The lowest proportion of students with A2 or lower is in Germany at $15 \%$, the highest in Turkey at $23.4 \%$. Only 1-3\% of students have an English level of $\mathrm{C} 1$ or higher (Table 1). 


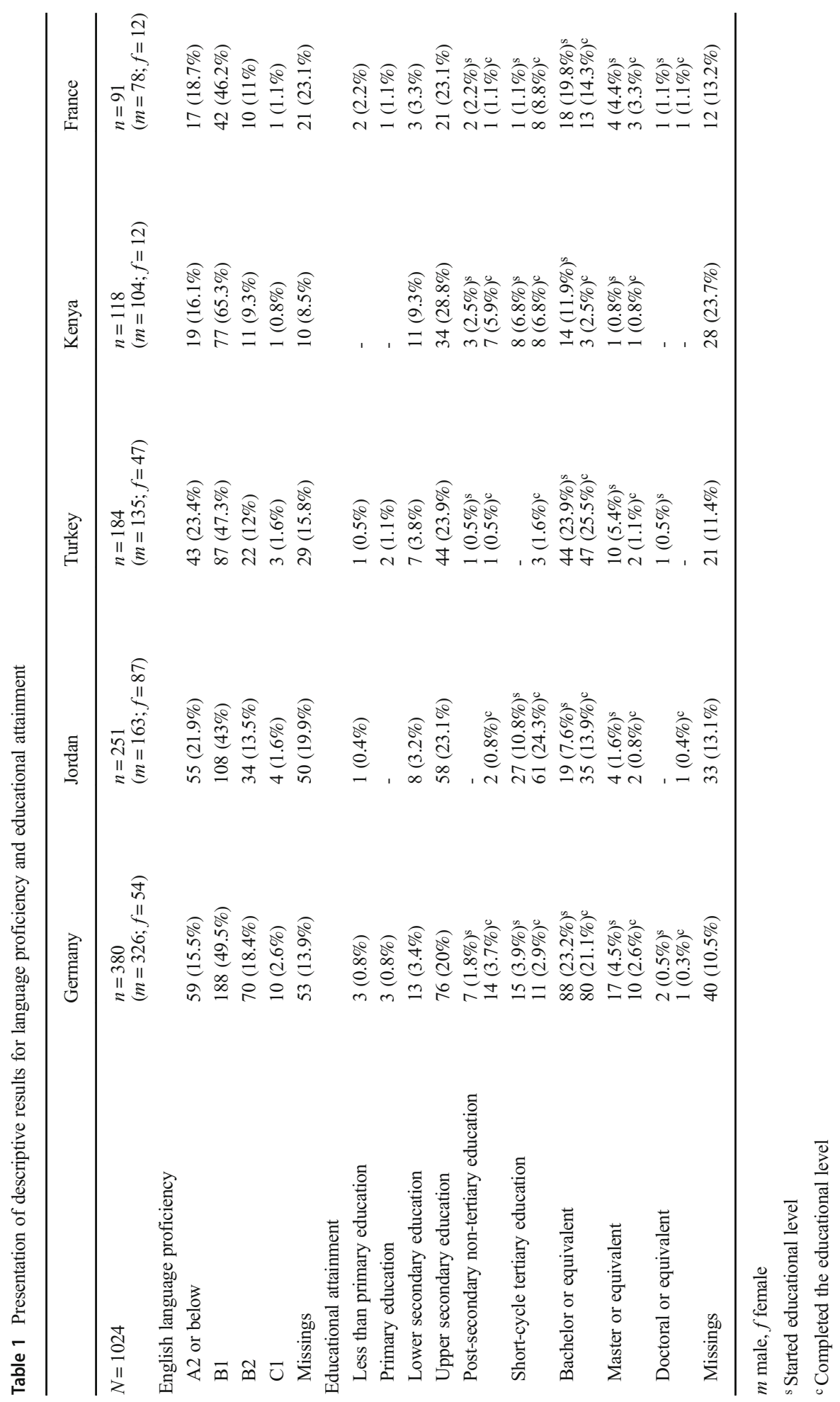


Most of the students in Germany indicated having a Bachelor's degree or higher $(52.2 \%)$. In Jordan, this figure is only $24.9 \%$ and in Turkey it is $56.4 \%$. In France, $44 \%$ indicated having a Bachelor's degree or higher, while in Kenya, only $16 \%$ have a Bachelor's degree or higher. A large proportion of students also stated upper secondary education as their educational level (from $20 \%$ in Germany to $28.8 \%$ in Kenya). A distinction was made as to whether the students had started the educational level or had already completed it (Table 1).

The standardized EAPs for motivation and intelligence show slightly negative results in all three variables. The intrinsic motivation is $M=0.031(S D=.86)$ for 898 students. Extrinsic motivation has a mean value of $M=-0.026(S D=.84)$ among 895 students. The average value of intelligence is $M=-0.015(S D=.86)$ for 545 students. The high variance of responses in the different variables is due to voluntary participation in the study.

\section{Regression Analysis}

For RQ1, linear regression models were used to analyze the prediction of the started and completed courses (DV) of the module Business English (Tables 2 and 3). All students attending the Business English module enroll in the study track business and economics ( $n=321$, of which $n=234$ male and $n=85$ female). A total of six courses are included in the Business English module. The refugee students started a maximum of four and a minimum of zero courses of the module and completed a maximum of three courses. The independent variables in this analysis were English proficiency, educational attainment, intrinsic and extrinsic study motivation, cognitive functioning, gender, and the current country of residence (Tables 2 and 3).

The results of the linear regression to predict the started courses showed significant influences of the variables gender $(B=.534 * * ; S E=.204)$, country of residence $\left(B_{\text {France }}=.121 ; S E=.116, B_{\text {Jordan }}=-.111 ; S E=.092, B_{\text {Kenya }}=.984 * * * ; S E=.135\right.$, $\left.B_{\text {Turkey }}=.084 ; S E=.158\right)$, and cognitive functioning (I-S-T) $(B=.162 * ; S E=.080)$. The results show that more courses are started if one is female, has higher IST scores, or lives in Kenya compared with someone living in Germany.

Women started an average of 0.99 courses $(S D=1.33)$ and completed an average of $0.41(S D=0.86)$ courses. Men started on average $0.48(S D=0.89)$ courses and completed $0.12(S D=0.89)$ courses. These results indicate that women started (Cohen's $d=0.47$ ) and completed (Cohen's $d=0.48$ ) more courses (Table 2).

The results of the linear regression to predict the completed courses of the module ( $n=$ $105)$ show significant influences on the variables gender $\left(B=.451^{*}, S E=.221\right)$, CEFR level $\left(B=-.272^{*}, S E=.120\right)$, and country of residence $\left(B_{\text {France }}=.716^{*}, S E=.292\right.$; $B_{\text {Jordan }}=.031, S E=.214 ; B_{\text {Kenya }}=.819^{* * *}, S E=.169 ; B_{\text {Turkey }}=.766, S E=.663$ ) (Table 3). The results show that more courses were completed if you are female, or if you are in Turkey or in France compared with someone in Germany. Furthermore, if the CEFR level rises, the number of completed courses is lower. People who are good in English do not complete the courses. There were no significant effects on motivation on the courses started or completed.

For RQ2, the Cox regression was performed to analyze the probability of remaining on the Kiron platform (Table 4). The event period was about 1 year, with an average survival rate of 100 days $(S D=95.068)$. 


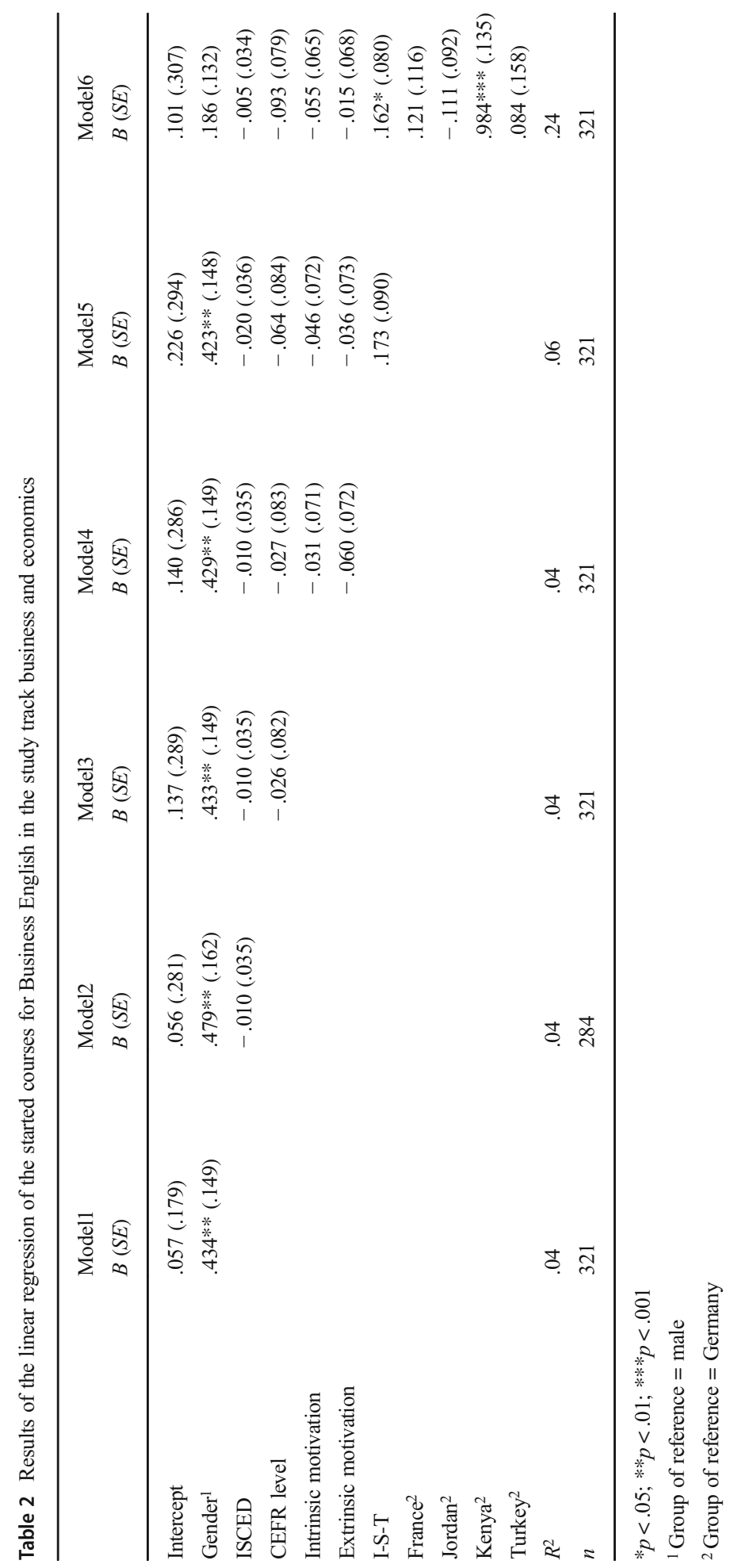




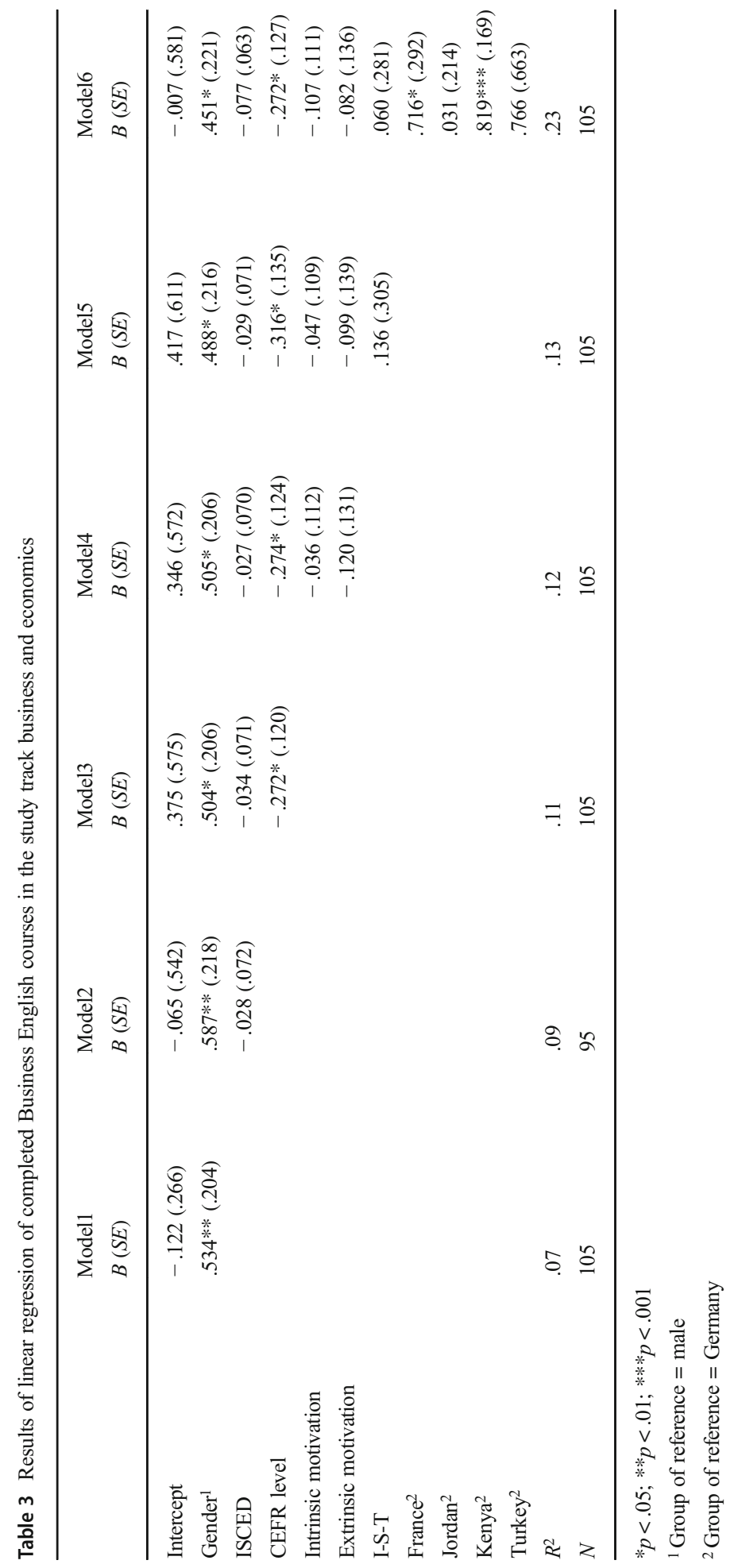




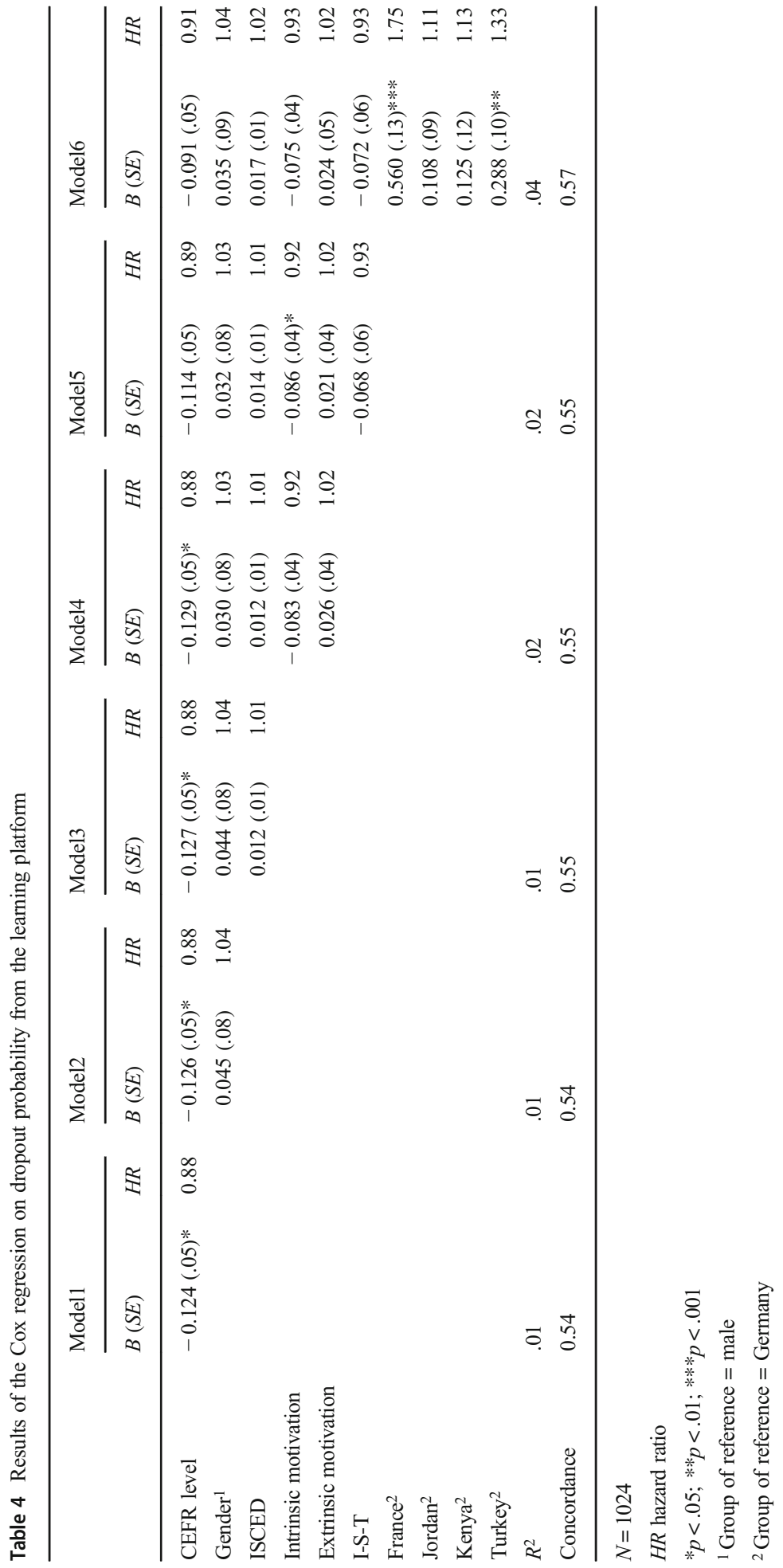


A semi-parametric model was calculated which assumes a linear distribution and has no specific prerequisites for the form of distribution. The general distribution assumptions in this model are unspecified, which is why only statements about the given survival period can be made (Wollschläger 2017).

Factors such as the CEFR level $\left(B=-.124^{*}, S E=.05\right)$, intrinsic motivation $(B=$ $\left.-.086^{*}, S E=.04\right)$, and the country of residence $\left(B_{\text {France }}=.560^{* * *}, S E=.13 ; B_{\text {Jordan }}=\right.$ $\left..108, S E=.09 ; B_{\text {Kenya }}=.125, S E=.12 ; B_{\text {Turkey }}=.288 * *, S E=.10\right)$ have effects on the dropout probability from the Kiron platform. The addition of the hazard ratio (HR) shows an increased risk for students from France as opposed to persons from Germany $(H R=1.75)$, as well as a higher risk for persons with a low CEFR level $(H R=.91)$ and low intrinsic motivation $(H R=.93)$ (see Fig. 2).

The low concordance indices $(.54-.57)$ and the low adjusted R2 of $2-4 \%$ indicate a low predictive power of the model, so that it must be assumed that further factors influence the dropout probability.

\section{Results of the Linear Regression Analysis of RQ1}

Results of the Cox Regression of RQ2

\section{Discussion}

\section{Refugee Students' Cognitive and Non-cognitive Characteristics and Their Impact on Academic Success and Dropout in Online Education}

The MOOCs generally show low completion rates of $15 \%$ or less (Breslow et al. 2013; Kizilcec et al. 2013; Liyanagunawardena et al. 2013). The completion rate for
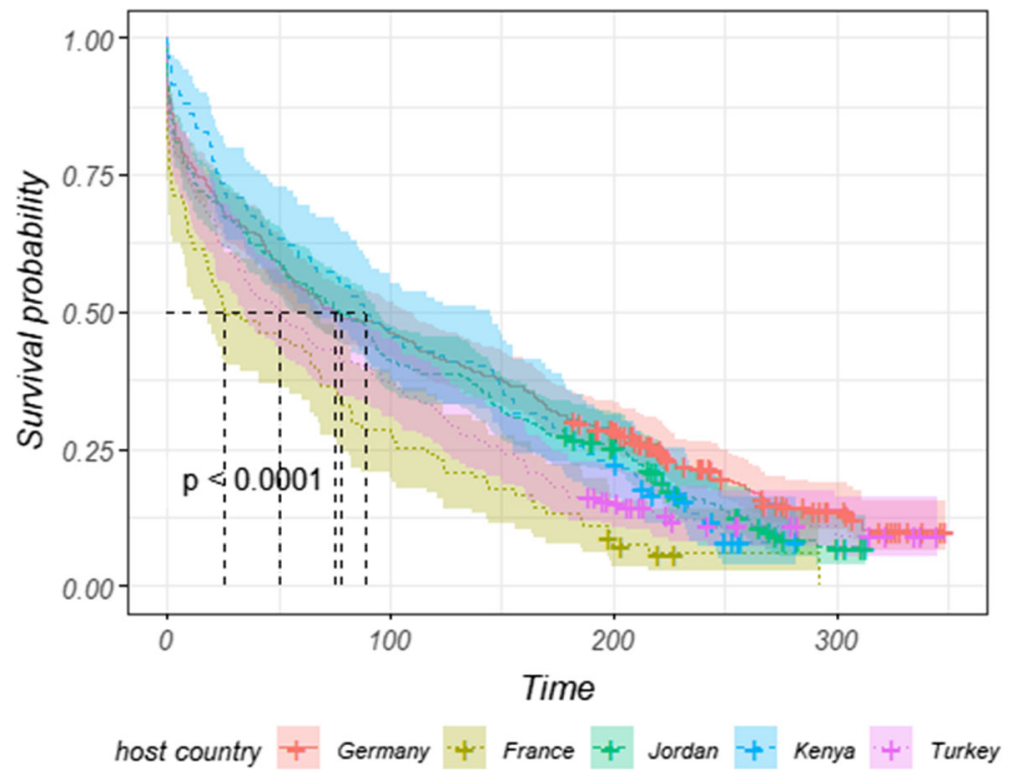

Fig. 2 The probability of survival separated by host countries 
the Business English module is also low in the presented results, averaging 0.61 $(S D=1.05)$.

Individual student characteristics are significant for participation in online programs (Liyanagunawardena et al. 2013; van de Oudeweetering and Agirdag 2018). The present results show - in line with expectations - that increasing the CEFR level reduces the risk of premature dropout from the platform. Studies on the academic achievement of refugee students point to the need for sufficient language proficiency, which is crucial for success (Platzer 2018). However, the language effect disappears in the hierarchical regression model. On the one hand, the study design influences this result, as the motivation to complete a Business English module may be lower if there is already high level of language proficiency. On the other hand, as Reinhardt et al. (2018) show, the ability to speak English differs depending on the country of residence. This can also be confirmed here on the basis of the descriptive results. It can be assumed that language proficiency and the countries of residence are confounded with each other and that the language effect therefore disappears.

The review of English proficiency only allows analyses of interindividual differences to better describe individual courses and to identify implications for the students. Here, a reciprocal effect of language proficiency through participation in the MOOCs can be assumed. As studies have shown, however, not only participation in the MOOCs but also participation in study-relevant forums and interaction with other students and lecturers influences the retention rate and the final grades (Gillani and Eynon 2014; Rovai 2003). It can also be assumed that they participate less in MOOCs-related communication due to poorer English proficiency (Reinhardt et al. 2018). Further research should therefore not only focus on the language level but also on the extent to which students participate in online studies and how language proficiency improves. A suitable construct for this would be academic language proficiency, so that fewer effects of general linguistic improvement are assessed (for limitations, see "Limitations").

In line with expectations, individual factors such as intelligence and motivation influence the predictive power of course participation and retention on the learning platform. The results of this study suggest that intelligence as an indicator of cognitive functions has at least some influence on the number of courses started. Further assumptions such as a connection to the educational level could not be confirmed. However, the use of this test for fluid intelligence covers only a small part of cognitive functioning. Even though the I-S-T 2000R is a well-established test instrument, the interpretation must take into account that the underlying normalization data were derived from a German sample. Therefore, it proves difficulty to make a statement on the basis of the comparison with the existing norm data.

In general, it is difficult to validate a highly heterogeneous sample from a wide variety of linguistic and cultural contexts with a single test instrument (Birman and Tran 2008; Harris et al. 2015; Kaplan 2009). The differences result from the different weighting of cognitive skills in culturalization. In Western cultures, for example, there is a strong focus on verbal skills. The type of test also leads to possible effects on the results. Multiple choice tests are not common in certain cultures and are therefore not understood. Also, matrix tests, which were treated as culture fair, show the same cultural bias as verbally oriented tests (Greenfield 1997; Rosselli and Ardila 2003). Kaplan (2009) describes that abnormalities in the intelligence testing of refugee 
children are also due to a lack of experience with performance tests, paper-pencil formats, and different task types. According to Kaplan (2009), the measurement is strongly caused by a culture bias, and it measures the actual cognitive abilities less than the absence of Western-normed cognitive abilities. Since the SUCCESS sample comes from 54 countries, we can assume that Western-cultured figural intelligence does not necessarily correspond to the intelligence structure of all 54 nations. For further investigation, it would therefore be advisable not only to use the isolated construct of intelligence but also rather to capture general cognitive functioning (e.g., executive functions, attention, or working memory) as this may reduce the cultural aspect (“Literature Review”).

Conclusions about motivation can only be partially confirmed in this study. There was a correlation between dropout probability and intrinsic motivation. The dropout probability decreases with higher intrinsic motivation. However, the common constructs of intrinsic and extrinsic motivation and their influence on academic performance are also influenced by Western research. Thus, the studies are conducted with Western country participants and the underlying theory corresponds to Western beliefs (Areepattamannil et al. 2011). The missing influence of extrinsic motivation in the present study could therefore be attributed less to motivational effects than to the underlying construct. In other studies that, for instance, used qualitative interviews (Hirano 2014) to assess motivation, high motivation on the part of the refugee students was reported.

The construct of extrinsic and intrinsic motivation is also viewed critically. Reiss (2012) comes to the conclusion that the two types cannot be clearly distinguished from each other. According to Reiss (2012), studies with statements on the connection between motivation in the educational context show different and contradictory results, which he explains is due to the poor reliability of the test instruments. Moreover, motivation is assessed, and the results are interpreted without formulating theory-based hypotheses about the expected effects.

Furthermore, there was little variation between the responses on the motivational scales ("Results"). On the one hand, this could be interpreted as the fact that everyone was motivated above average, but it no longer allows for differential hypotheses. Moreover, there are certainly response tendencies in the sense of social desirability. On the other hand, additional studies should not only look at motivation in isolation. Results from other success studies also describe the influence of subject-related interest with subject-related competence and influence expectations as valid indicators for self-assessment (Marsh and Martin 2011; Schunk and Pajares 2005).

Kizilcec et al. (2013) pointed out that MOOCs users are mostly male and male users are more likely to conclude MOOCs than female users. However, the available results point to an opposite gender effect. Other studies also point to a higher proportion of women in online education (Wojciechowski and Palmer 2005). This study showed that female refugee students tend to start more courses and also complete more courses of the English module. However, there was no effect of gender on the dropout probability. The results of this study are somewhat encouraging. Even though male refugee students have a head start in online education, female refugee students are more active and successful in their online studies. 


\section{Limitations}

The results of the present study provide interesting insights into possible correlations between individual factors and the academic performance of refugee students. Nevertheless, the study also has limitations. The studies on the probability of completion are limited to one module of the study track business and economics. These limitations were necessary because there was no complete data on the completion rate of other study-relevant modules and their start at the time of the study. Therefore, no general statement can be made for the entire sample or beyond.

The absence of some expected effects can be attributed to using the research method of computer-based testing. Using online testing to assess cognitive abilities is seen as a necessary development with many advantages. It allows for more precise and timeeffective implementation and evaluation, which can also reach minority groups (Desideri et al. 2016). Morrison et al. (2015) pointed out, however, that a matrix test showed lower retest reliability compared with the paper-pencil format. The unsupervised test situation may lead to biased results (Morrison et al. 2015).

Furthermore, the English language proficiency assessment was conducted through a one-time measurement using the $C$-test. As already shown in the section about the current state of research, an assessment of academic language proficiency would possibly be more suitable as a valid predictor for study success. In addition, the one-time assessment at the beginning of studies does not allow for any conclusions about a possible increase in language proficiency over the course of study on the online platform. To be able to make predictive statements about retention in the study, a measurement of how language proficiency increases over the course of study would be required.

\section{Conclusion}

\section{Making Higher Education Accessible}

The results of this study provide insights into an increasingly important field that few studies have examined so far. The integration of different student groups, especially vulnerable ones, is one of the main challenges of HE institutions. Online education is considered a promising approach to integrating refugees into HE. However, the results of this study show that certain factors can affect the academic achievements and likelihood of dropout of refugee students in online education. Sociodemographic factors (e.g., gender), cognitive factors (e.g., English proficiency), and external factors (e.g., country of residence) have a significant influence on study retention.

As this study demonstrated, the identification of individual student characteristics, which determine the retention of students in online studies, is highly relevant for participating institutions such as providers of online education, universities, and teachers (Wojciechowski and Palmer 2005). In particular, the great heterogeneity among non-traditional students needs to be taken into account (Wojciechowski and Palmer 2005). Especially, refugees as part of the non-traditional learner group have an increased risk of dropping out of a chosen educational path due to their pre-migration factors such as interrupted education or problems such as post-settlement factors (Earnest et al. 2010; Wong et al. 2018). 
Although online education is often seen as an approach to overcoming possible barriers to integration, known problems such as high dropout rates and perceived social isolation need to be considered (Willging and Johnson 2009). It is therefore important to examine student behavior in online education longitudinally in future research to identify the most significant challenges and address them in educational practice to promote successful integration. Based on these results, support measures can be specially adapted to the needs of the refugee student group to increase their academic performance and to reduce their likelihood of dropping out (Gillani and Eynon 2014).

\section{Acknowledgements Open Access funding provided by Projekt DEAL.}

Open Access This article is licensed under a Creative Commons Attribution 4.0 International License, which permits use, sharing, adaptation, distribution and reproduction in any medium or format, as long as you give appropriate credit to the original author(s) and the source, provide a link to the Creative Commons licence, and indicate if changes were made. The images or other third party material in this article are included in the article's Creative Commons licence, unless indicated otherwise in a credit line to the material. If material is not included in the article's Creative Commons licence and your intended use is not permitted by statutory regulation or exceeds the permitted use, you will need to obtain permission directly from the copyright holder. To view a copy of this licence, visit http://creativecommons.org/licenses/by/4.0/.

\section{References}

Adebayo, B. (2008). Cognitive and non-cognitive factors: affecting the academic performance and retention of conditionally admitted freshmen. Journal of College Admission, 200, 15-21.

AERA Code of Ethics: American Educational Research Association Approved by the AERA Council February 2011. (2011). Educational Researcher, 40(3), 145-156. https://doi.org/10.3102/0013189 X11410403.

Afzal, H., Ali, I., Khan, M. A., \& Hamid, K. (2010). A study of university students' motivation and its relationship with their academic performance. International Journal of Business and Management, 5(4), 80-88.

Areepattamannil, S., Freeman, J. G., \& Klinger, D. A. (2011). Intrinsic motivation, extrinsic motivation, and academic achievement among Indian adolescents in Canada and India. Social Psychology of Education, 14, 427-439.

Baker, S., Irwin, E., Freeman, H., Nance, S., \& Coleman, J. (2018a). Building cultural and linguistic bridges: reflections on a program designed to support adult students from refugee backgrounds' transitions into university. Journal of Academic Language and Learning, 12(1), 64-80.

Baker, S., Ramsay, G., Irwin, E., \& Miles, L. (2018b). 'Hot', 'Cold' and 'Warm' supports: towards theorising where refugee students go for assistance at university. Teaching in Higher Education, 23(1), 1-16.

Biewen, M., Happ, R., Schmidt, S., \& Zlatkin-Troitschanskaia, O. (2018). Knowledge growth, academic beliefs and motivation of students in business and economics-a longitudinal German case study. Higher Education Studies, 8, 9-28.

Birman, D., \& Tran, N. (2008). Psychological distress and adjustment of Vietnamese refugees in the United States: association with pre- and postmigration factors. American Journal of Orthopsychiatry, 78(1), 109120.

Birnbaum, A. (1957). Efficient design and use of tests of ability for various decision-making problems. USAF School of Aviation Medicine, Series Report No. 58-16, Project No. 7755-23. Randolph Air Force Base, Texas: January.

Bock, R. D., \& Aitkin, M. (1981). Marginal maximum likelihood estimation of item parameters: application of an EM algorithm. Psychometrika, 46(4), 443-459.

Bond, T. G., \& Fox, C. M. (2007). Applying the Rasch model: fundamental measurement in the human sciences (2nd ed.). Mahwah, NJ: Lawrence Erlbaum. 
Breslow, L., Pritchard, D. E., DeBoer, J., Stump, G. S., Ho, A. D., \& Seaton, D. T. (2013). Studying learning in the worldwide classroom research into edX's first MOOC. Research and Practice in Assessment, 8, $13-25$.

Campion, E. D. (2018). The career adaptive refugee: exploring the structural and personal barriers to refugee resettlement. Journal of Vocational Behavior, 105, 6-16.

Castaño-Muñoz, J., Colucci, E., \& Smidt, H. (2018). Free digital learning for inclusion of migrants and refugees in Europe: a qualitative analysis of three types of learning purposes. The International Review of Research in Open and Distributed Learning, 19(2).

Cattell, R. B. (1987). Intelligence: its structure, growth and action: its structure, growth and action. Amsterdam: Elsevier Science Publishers B.V.

Cheung, S. Y., \& Phillimore, J. (2017). Gender and refugee integration: a quantitative analysis of integration and social policy outcomes. Journal of Social Policy, 46(2), 211-230.

Clifford, A., Lang, L., Chen, R., Anstey, K. J., \& Seaton, A. (2016). Exposure to air pollution and cognitive functioning across the life course-a systematic literature review. Environmental Research, 147, 383-398.

Council of Europe, Council for Cultural Cooperation, Education Committee, \& Modern Languages Division. (2001). Common European framework of reference for languages: learning, teaching, assessment. Cambridge: Cambridge University Press.

Council of Europe, Council for Cultural Cooperation, Education Committee, \& Modern Languages Division. (2018). Common European framework of reference for languages: learning, teaching, assessment. In Companion Volume with new descriptors. Cambridge: Cambridge University Press.

Cox, D. R. (1972). Regression models and life tables (with discussion). Journal of the Royal Statistical Society, Series B, 34, 187-220.

Datzberger, S., \& Le Mat, M. L. (2018). Just add women and stir?: education, gender and peacebuilding in Uganda. International Journal of Educational Development, 59, 61-69.

De Waard, I., Gallagher, M. S., Zelezny-Green, R., Czerniewicz, L., Downes, S., Kukulska-Hulme, A., \& Willems, J. (2014). Challenges for conceptualising EU MOOC for vulnerable learner groups. Proceedings of the European MOOC Stakeholder Summit, 2014, 33-42.

Deci, E. L., \& Ryan, R. M. (1985). Die Selbstbestimmungstheorie der Motivation und ihre Bedeutung für die Pädagogik. Zeitschrift für Pädagogik, 39(2), 223-238.

Desideri, L., Tarabelloni, G., Nanni, I., Malavasi, M., Nori, R., \& Bonifacci, P. (2016). An eye-controlled version of the Kaufman Brief Intelligence Test 2 (KBIT-2) to assess cognitive functioning. Computers in Human Behavior, 63, 502-508.

Dryden-Peterson, S., Dahya, N., \& Adelman, E. (2017). Pathways to educational success among refugees: connecting locally and globally situated resources. American Educational Research Journal, 54(6), 1011-1047.

Earnest, J., Joyce, A., de Mori, G., \& Silvagni, G. (2010). Are universities responding to the needs of students from refugee backgrounds? Australian Journal of Education, 54(2), 155-174.

El Jack, A. (2012). "Education is my mother and father": the "invisible" women of Sudan. Refuge: Canada's Journal on Refugees, 27(2).

El-Ghali, H. A., \& Al-Hawamdeh, A. (2017). Higher education and Syrian refugee students: the case of Jordan. Policies, Practices, and Perspectives. Beirut: UNESCO Regional Bureau for Education in the Arab States/Issam Fares Institute for Public Policy and International Affairs.

Enders, C. (2010). Applied missing data analysis. New York: Guilford Press.

Engle, D., Mankoff, C., \& Carbrey, J. (2015). Coursera's introductory human physiology course: factors that characterize successful completion of a MOOC. The International Review of Research in Open and Distributed Learning, 16(2).

Ferede, M. K. (2012). Structural factors associated with higher education access for first-generation refugees in Canada: an agenda for research. Refuge: Canada's Journal on Refugees, 27(2), 79-88.

Figueiredo, S., Martins, M. A., \& da Silva, C. F. (2018). Psychological distress of immigrant population in host school systems and the critical period for second language development: a review. Clinical and Experimental Psychology, 4, 192. https://doi.org/10.4172/2471-2701.1000192.

Fisher, G. G., Chaffee, D. S., Tetrick, L. E., Davalos, D. B., \& Potter, G. G. (2017). Cognitive functioning, aging, and work: a review and recommendations for research and practice. Journal of Occupational Health Psychology, 22(3), 314-336.

Fonteyne, L., Duyck, W., \& De Fruyt, F. (2017). Program-specific prediction of academic achievement on the basis of cognitive and non-cognitive factors. Learning and Individual Differences, 56, $34-48$.

Gillani, N., \& Eynon, R. (2014). Communication patterns in massively open online courses. The Internet and Higher Education, 23, 18-26. 
Greene, J. A., Oswald, C. A., \& Pomerantz, J. (2015). Predictors of retention and achievement in a massive open online course. American Educational Research Journal, 52(5), 925-955.

Greenfield, P. M. (1997). You can't take it with you: why ability assessments don't cross cultures. American Psychologist, 52(10), 1115-1124.

Grigorenko, M. (2015). A brief introduction to academic language. Education Faculty Publications. 73. Retrieved from: https://digitalcommons.cedarville.edu/education_publications/73

Grotjahn, R. (1987). How to construct and evaluate a C-test: a discussion of some problems and some statistical analyses. Taking their measure: The validity and validation of language tests, 219-253.

Grotjahn, R. (Ed.). (2002). The C-test: theory, empirical research, applications. Frankfurt am Main: Lang.

Guerra-Carrillo, B., Katovich, K., \& Bunge, S. A. (2017). Does higher education hone cognitive functioning and learning efficacy? Findings from a large and diverse sample. PLoS One, 12(8), e0182276.

Haag, N., Heppt, B., Stanat, P., Kuhl, P., \& Pant, H. A. (2013). Second language learners' performance in mathematics: disentangling the effects of academic language features. Learning and Instruction, 28, 24 34.

Haag, N., Heppt, B., Roppelt, A., \& Stanat, P. (2015). Linguistic simplification of mathematics items: effects for language minority students in Germany. European Journal of Psychology of Education, 30(2), 145167.

Halawa, S., Greene, D., \& Mitchell, J. (2014). Dropout prediction in MOOCs using learner activity features. Proceedings of the Second European MOOC Stakeholder Summit, 58-65.

Harris, A., Marlowe, J., \& Nyuon, N. (2015). Rejecting Ahmed's 'melancholy migrant': South Sudanese Australians in higher education. Studies in Higher Education, 40(7), 1226-1238.

Harsch, C., \& Hartig, J. (2015). Comparing C-tests and yes/no vocabulary size tests as predictors of receptive language skills. Language Testing, 33(4), 555-575.

Hatoss, A., \& Huijser, H. (2010). Gendered barriers to educational opportunities: Resettlement of Sudanese refugees in Australia. Gender and Education, 22(2), 147-160.

Hirano, E. (2014). Refugees in first-year college: academic writing challenges and resources. Journal of Second Language Writing, 23, 37-52.

Hos, R. (2016). The lives, aspirations, and needs of refugee and immigrant Students with Interrupted Formal Education (SIFE) in a Secondary Newcomer Program. Urban Education, 1-24. https://doi.org/10.1177 $/ 0042085916666932$.

Joyce, A., Earnest, J., De Mori, G., \& Silvagni, G. (2010). The experiences of students from refugee backgrounds at universities in Australia: Reflections on the social, emotional and practical challenges. Journal of Refugee Studies, 23(1), 82-97.

Kaplan, I. (2009). Effects of trauma and the refugee experience on psychological assessment processes and interpretation. Australian Psychologist, 44(1), 6-15.

Kassambara, K., \& Kosinski, M. (2018). survminer: drawing survival curves using 'ggplot2'. R package version 0.4.2.

Kennedy, G., Coffrin, C., De Barba, P., \& Corrin, L. (2015, March). Predicting success: how learners' prior knowledge, skills and activities predict MOOC performance. In Proceedings of the fifth international conference on learning analytics and knowledge (pp. 136-140). ACM.

Khalil, H., \& Ebner, M. (2014). MOOCs completion rates and possible methods to improve retention-a literature review. In Proceeding of world conference on educational multimedia, hypermedia and (pp. 1236-1244). Chesapeake, VA: AACE.

Kivling-Bodén, G., \& Sundbom, E. (2003). Cognitive abilities related to post-traumatic symptoms among refugees from the former Yugoslavia in psychiatric treatment. Nordic Journal of Psychiatry, 57(3), 191198.

Kizilcec, R. F., Piech, C., \& Schneider, E. (2013). Deconstructing disengagement: analyzing learner subpopulations in massive open online courses. In Proceedings of the third international conference on learning analytics and knowledge (pp. 170-179). ACM.

Knappert, L., Kornau, A., \& Figengül, M. (2018). Refugees' exclusion at work and the intersection with gender: insights from the Turkish-Syrian border. Journal of Vocational Behavior, 105, 62-82. https://doi. org/10.1016/j.jvb.2017.11.002.

Liepmann, D., Beauducel, A., Brocke, B., \& Amthauer, R. (2007). Intelligenz-Struktur-Test 2000 R [Intelligence Structure Test 2000 R]. Göttingen: Hogrefe.

Littlejohn, A., Hood, N., Milligan, C., \& Mustain, P. (2016). Learning in MOOCs: motivations and selfregulated learning in MOOCs. The Internet and Higher Education, 29, 40-48.

Liyanagunawardena, T. R., Williams, S., \& Adams, A. (2013). The impact and reach of MOOCs: a developing countries' perspective. eLearning papers, 38-46. 
Lleras, C. (2008). Do skills and behaviors in high school matter? The contribution of noncognitive factors in explaining differences in educational attainment and earnings. Social Science Research, 37(3), 888-902.

Marsh, H. W., \& Martin, A. J. (2011). Academic self-concept and academic achievement: Relations and causal ordering. British Journal of Educational Psychology, 81, 59-77.

Milligan, C., Littlejohn, A., \& Margaryan, A. (2013). Patterns of engagement in connectivist MOOCs. MERLOT Journal of Online Learning and Teaching, 9(2).

Morrison, G. E., Simone, C. M., Ng, N. F., \& Hardy, J. L. (2015). Reliability and validity of the NeuroCognitive Performance Test, a web-based neuropsychological assessment. Frontiers in Psychology, 6, 1652.

Muraki, E. (1992). A generalized partial credit model: application of an EM algorithm. ETS Research Report Series, 1992(1), i-30.

Muthén, B. O., \& Muthén, L. (2012). Mplus computer program version 7.3. Mplus, Los Angeles, California, $1-711$.

Norris, J. M. (2006). Development and evaluation of a curriculum-based German C-test for placement purposes. In R. Grotjahn (Ed.), The C-test: theory, empirical research, applications (pp. 45-83). Frankfurt am Main: Lang.

O'Shea, S., Lysaght, P., Roberts, J., \& Harwood, V. (2016). Shifting the blame in higher education-social inclusion and deficit discourses. Higher Education Research \& Development, 35(2), 322-336.

Office for Standards in Education (OFSTED). (2001). Inspecting English as an additional language: 11-16 with guidance on self-evaluation. London: OFSTED.

Ogundokun, M. O., \& Adeyemo, D. A. (2010). Emotional intelligence and academic achievement: the moderating influence of age, intrinsic and extrinsic motivation. In The African Symposium (Vol. 10, No. 2, pp. 127-141).

Packham, G., Jones, P., Miller, C., \& Thomas, B. (2004). E-learning and retention: key factors influencing student withdrawal. Education+ Training, 46(6/7), 335-342.

Pagel, L., Richter, D., \& Schupp, J. (2018). Kognitive Potenziale von Geflüchteten. In H. Brücker, N. Rother \& J. Schupp (Eds.), IAB-BAMF-SOEP-Befragung von Geflüchteten 2016: Studiendesign, Feldergebnisse sowie Analysen zu schulischer wie beruflicher Qualifikation, Sprachkenntnissen sowie kognitiven Potenzialen (No. 123). DIW Berlin: Politikberatung kompakt.

Pedaste, M., Must, O., Silm, G., Täht, K., Kori, K., Leijen, Ä., \& Mägi, M. L. (2015). How do cognitive ability and study motivation predict the academic performance of IT students? In ICERI conference 8th International Conference of Education, Research and Innovation (pp. 7167-7176). IATED Academy.

Pittaway, E., \& Bartolomei, L. (2001). Refugees, race, and gender: the multiple discrimination against refugee women. Refuge: Canada's Journal on Refugees, 19(6).

Platzer, M. (2018). Refugee access to tertiary education. In Refugees and migrants in law and policy (pp. 191205). Cham: Springer.

Puerta Morales, L. (2015). Relationship between cognitive processes and academic performance in high school students: Relación entre los procesos cognitivos y el rendimiento académico en estudiantes de educación básica secundaria. Psychologia. Avances de la disciplina, 9(2), 85-100.

R Core Team. (2018). R: a language and environment for statistical computing. Vienna, Austria: R Foundation for Statistical Computing Retrieved from: https://www.R-project.org/.

Reinhardt, F., Zlatkin-Troitschanskaia, O., Deribo, T., Happ, R., \& Nell-Müller, S. (2018). Integrating refugees into higher education-the impact of a new online education program for policies and practices. Policy Reviews in Higher Education, 1-29.

Reiss, S. (2012). Intrinsic and extrinsic motivation. Teaching of Psychology, 39(2), 152-156.

Robitzsch, A., Kiefer, T., \& Wu, M. (2018). TAM: test analysis modules. $R$ package version, 2, 8-21 Retrieved from: https://CRAN.R-project.org/package=TAM.

Rosselli, M., \& Ardila, A. (2003). The impact of culture and education on non-verbal neuropsychological measurements: a critical review. Brain and Cognition, 52(3), 326-333.

Rovai, A. P. (2003). In search of higher persistence rates in distance education online programs. The Internet and Higher Education, 6(1), 1-16.

Rubin, D. B. (1976). Inference and missing data. Biometrika, 63(3), 581-592.

Rushton, J. P., Čvorović, J., \& Bons, T. A. (2007). General mental ability in South Asians: data from three Roma (Gypsy) communities in Serbia. Intelligence, 35(1), 1-12.

Ryan, R. M., \& Deci, E. L. (2000). Intrinsic and extrinsic motivations: classic definitions and new directions. Contemporary Educational Psychology, 25(1), 54-67.

Schiefele, U., Krapp, A., Wild, K. P., \& Winteler, A. (1993). Der "Fragebogen zum Studieninteresse" (FSI). Diagnostica, 39(4), 335-351. 
Schleppegrell, M. J. (2001). Linguistic features of the language of schooling. Linguistics and Education, 12(4), 431-459. https://doi.org/10.1016/S0898-5898(01)00073-0.

Schunk, D. H., \& Pajares, F. (2005). Competence perceptions and academic functioning. Handbook of competence and motivation, 85, 104.

Schwenck, C., Dummert, F., Endlich, D., \& Schneider, W. (2015). Cognitive functioning in children with learning problems. European Journal of Psychology of Education, 30(3), 349-367.

Suter, R., Harsch, C., \& Brandt, S. (2017). Entwicklung eines Englisch-Einstufungstests für Geflüchtete [Development of an English placement test for refugees]. Presented at the annual conference of the Gesellschaft für Empirische Bildungsforschung [Society for Empirical Educational Research], Heidelberg. Retrieved from http://www.gebf2017.de/aktuelles/abstracts_Einzelbeitraege_GEBF2017_030317.pdf

Therneau, T. (2015). A package for survival analysis in $S$ (Version 2.38). Retrieved from: https://CRAN.Rproject.org/package=survival $>$.

Townsend, D., \& Collins, P. (2009). Academic vocabulary and middle school English learners: an intervention study. Reading and Writing, 22(9), 993-1019. https://doi.org/10.1007/s11145-008-9141-y.

UNESCO Institute for Statistics. (2012). International Standard Classification of Education ISCED 2011. Retrieved from: http:/www.uis.unesco.org

Van Buuren, S., \& Groothuis-Oudshoorn, K. (2010). mice: multivariate imputation by chained equations in R. Journal of Statistical Software, 45(3), 1-67.

van de Oudeweetering, K., \& Agirdag, O. (2018). MOOCs as accelerators of social mobility? A systematic review. Journal of Educational Technology \& Society, 21(1), 1-11.

Volery, T., \& Lord, D. (2000). Critical success factors in online education. International Journal of Educational Management, 14(5), 216-223.

Von Stumm, S., Hell, B., \& Chamorro-Premuzic, T. (2011). The hungry mind: Intellectual curiosity is the third pillar of academic performance. Perspectives on Psychological Science, 6(6), 574-588.

Watkins, P. G., Razee, H., \& Richters, J. (2012). 'I'm telling you... the language barrier is the most, the biggest challenge': Barriers to education among Karen refugee women in Australia. Australian Journal of Education, 56(2), 126-141.

Willging, P. A. \& Johnson, S. D. (2009). Factors that influence students' decision to dropout of online courses. Journal of Asynchronous Learning Networks, 13(3), 115-127.

Wojciechowski, A., \& Palmer, L. B. (2005). Individual student characteristics: can any be predictors of success in online classes. Online journal of distance learning administration, 8(2), 13.

Wollschläger, D. (2017). Grundlagen der Datenanalyse mit R: eine anwendungsorientierte Einführung. 4. Aufl. Berlin: Springer.

Wong, C. W., \& Schweitzer, R. D. (2017). Individual, premigration and postsettlement factors, and academic achievement in adolescents from refugee backgrounds: a systematic review and model. Transcultural Psychiatry, 54(5-6), 756-782.

Wong, C. W., Schweitzer, R. D., \& Khawaja, N. G. (2018). Individual, pre-migration, and post-settlement factors in predicting academic success of adolescents from refugee backgrounds: a 12-month follow-up. Journal of International Migration and Integration, 1-23.

Ye, C., \& Biswas, G. (2014). Early prediction of student dropout and performance in MOOCs using higher granularity temporal information. Journal of Learning Analytics, 1(3), 169-172.

Zlatkin-Troitschanskaia, O., Happ, R., Nell-Müller, S., Deribo, T., Reinhardt, F., \& Toepper, M. (2018).Successful integration of refugee students in higher education: Insights from entry diagnostics in an online study program. Global Education Review, 5(4), 158-181.

Publisher's Note Springer Nature remains neutral with regard to jurisdictional claims in published maps and institutional affiliations. 